\section{Um país dividido? \\ Condicionantes do voto nas eleições presidenciais brasileiras de 2014}

[A divided country?

Determinants of the vote in the

2014 Brazilian presidential elections]

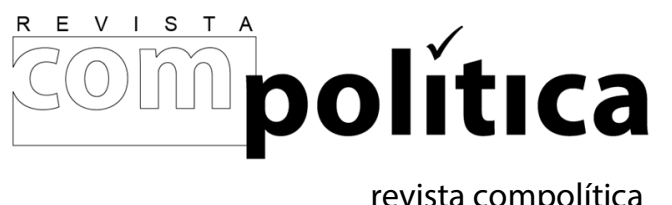

revista compolítica 2018, vol. 8(1)

compolitica.org/revista

ISSN: 2236-4781

DOI: 10.21878/compolitica.2018.8.1.140

O Open Access Journal

\author{
Vinícius S. Alves \\ Universidade de Brasília \\ [University of Brasília]

\section{lana A. Lima} \\ Universidade de Brasília \\ [University of Brasília]
}

\begin{abstract}
Resumo
O objetivo deste trabalho é esclarecer quais foram os principais fatores explicativos do voto em Dilma Rousseff nas eleições de 2014. O mencionado pleito foi marcado por um amplo debate nas redes sociais e nos tradicionais meios de comunicação a respeito de uma polarização do eleitorado brasileiro. Neste sentido, o artigo busca verificar se, e em torno de quais fatores, os eleitores se dividiram naquelas eleições. Utilizando modelos de regressão logística, apontamos os principais vetores explicativos do voto no primeiro e no segundo turnos em 2014. Os resultados sugerem que idade, região, ter ou não votado em Dilma na eleição anterior, ideologia e interesse por política, de fato, auxiliaram a explicar o voto na presidente eleita. Além disso, observamos que o formato da competição em dois turnos intensificou a polarização do eleitorado.
\end{abstract}

Palavras-chave: eleições presidenciais, comportamento eleitoral, voto.

\begin{abstract}
This paper aims to clarify what were the main explanatory factors to the vote for Dilma Rousseff in the 2014 elections. In this election, there was a broad debate in the media regarding a polarization of the Brazilian constituency. In this sense, the paper seeks to verify if, and around which factors, the Brazilian voters were divided in these elections. Using two logistic regression models, we point out, at the end, the main explanatory factors for the vote in the first and second rounds in 2014. The results suggest that some features of the voters, such as age, region, whether or not they voted for Dilma in the previous election, ideology, and political interest, in fact, help us to explain the vote for the elected president. Besides that, we noticed that the runoff election has intensified the polarization of the constituency.
\end{abstract}

Keywords: presidential elections, electoral behavior, vote. 


\section{Um país dividido? Condicionantes do voto nas eleições presidenciais brasileiras de 2014}

Vinícius S. ALVES Iana A. LIMA

s eleições presidenciais de 2014 foram marcadas por um intenso debate a
respeito de uma suposta divisão acirrada do eleitorado brasileiro em grupos.
Nos tradicionais meios de comunicação e também nas redes sociais, argumentava-se, com frequência, que existia uma maior ou menor concentração de votos nos principais candidatos, Dilma Rousseff e Aécio Neves, em torno de determinadas características dos indivíduos.

Os jornais endossavam a ótica de um país dividido. A origem geográfica dos eleitores, sua condição socioeconômica e até mesmo características mais intrínsecas aos indivíduos eram apontadas como justificativas para a afirmação de que o país havia se fracionado no mencionado pleito.

A expressiva votação do candidato derrotado associada à estreita margem que garantiu a vitória de Dilma corroboravam algumas análises realizadas neste sentido, o que, para alguns, seria um indício de que o resultado das eleições de 2014 deixava claro que o êxito da presidente eleita poderia ser atribuído à preferência de determinados grupos, em detrimento de outros.

Nessa ordem de ideias, este artigo tem como objetivo examinar se, de fato, existiu uma divisão acirrada do eleitorado brasileiro em torno de determinadas características dos cidadãos. Desse modo, pretende-se analisar se é possível identificar grupos aos quais podemos atribuir a vitória da presidente eleita, o que pensamos ser imprescindível para uma afirmação de que o país se encontrava dividido.

Assim, este trabalho se orienta em torno das seguintes perguntas: quais foram os principais fatores que aumentaram as chances do voto em Dilma Rousseff nas eleições de 2014? É 
possível identificar uma divisão do eleitorado brasileiro em torno de características socioeconômicas, demográficas e outras mais relacionadas ao arranjo políticoinstitucional? Para tanto, o artigo utiliza dados do ESEB (Estudo Eleitoral Brasileiro) daquele ano com o intuito de identificar características dos indivíduos que contribuíram para a decisão do voto na candidata vitoriosa.

Após essa breve introdução, na qual apresentamos o contexto que motivou a pesquisa, realizamos, na seção seguinte, uma revisão de literatura que consideramos relevante para se compreender o processo de formação de preferências dos eleitores, especialmente num contexto político como o brasileiro, marcado notadamente por um complexo arranjo de instituições que dividem atribuições entre entes federativos e também por um sistema de partidos pouco conectado à sociedade, para dizer o mínimo.

Na terceira seção, destinada à explicitação dos procedimentos metodológicos, detalhamos como foi realizada a análise empírica e apresentamos os dois modelos de regressão logística desenhados com o intuito de analisar o voto no primeiro e segundo turnos da eleição de 2014.

Por sua vez, na quarta seção, discutimos os resultados obtidos por meio do exame dos dados do ESEB de 2014, momento em que serão apontadas quais as variáveis dentre as selecionadas se mostraram mais relevantes para compreender o voto em Dilma Rousseff.

Por fim, após uma breve síntese dos principais pontos do artigo, apresentamos uma reflexão sobre a famigerada divisão do eleitorado no mencionado pleito, realizada à luz do contexto político brasileiro, além das limitações deste trabalho, apontamentos e desdobramentos para estudos posteriores.

\section{As instituições e a competição política no Brasil}

No Brasil e em outras democracias, especialmente entre as mais recentes, a fragmentação partidária é um fenômeno que tem sido objeto de estudo recorrente entre os cientistas políticos. Grande parte da literatura argumenta que uma fragmentação excessiva tem 
impacto negativo na manutenção de regimes presidencialistas e que, portanto, deve ser aspecto de grande atenção na análise de arranjos institucionais (Golder, 2006).

Neste momento, salienta-se que existe uma série de fatores institucionais que podem impactar a competição política e, consequentemente, a fragmentação partidária. Dentre esses aspectos estão desde o regime de governo (Hicken; Stoll, 2011), a heterogeneidade social e permissividade do sistema eleitoral (Amorim Neto; Cox, 1997), passando pela centralização do Executivo, pelo impacto da estrutura das listas (Santos, 2006), magnitude do distrito, sistema proporcional, turno único ou runoff, entre outros.

Um fator recentemente destacado na literatura é o impacto das eleições presidenciais nas eleições legislativas, o efeito coattails. Por meio deste, considerando a proximidade das eleições do Executivo e Legislativo nacional e um número reduzido de candidatos presidenciais, poderia se observar a maior coordenação dos partidos em direção a um dos candidatos e consequente redução da fragmentação partidária (Golder, 2006).

Isso se daria em virtude do efeito redutor dos partidos no nível dos distritos a partir da tentativa de alinhamento com um dos candidatos presidenciáveis e também pelo aumento da coordenação entre distritos eleitorais (Hicken; Stoll, 2011). Esse fenômeno ocorreria devido ao comportamento estratégico de partidos e eleitores, uma vez que os votantes tomariam a corrida presidencial como um atalho cognitivo com relação a questões programáticas de governo. Os partidos, ao perceberem isso, buscariam se alinhar a um dos candidatos aproveitando esse shortcut, além de beneficiarem-se da organização da campanha, espaço na mídia, entre outros recursos (Golder, 2006; Hicken; Stoll, 2011).

No caso brasileiro, no entanto, a realidade foge à regra teórica. Observa-se que mesmo com a unificação do calendário eleitoral, a partir das eleições de 1994, não houve a redução da fragmentação partidária. Pelo contrário, observa-se um aumento crescente de legendas na Câmara dos Deputados, a despeito da proximidade das eleições presidenciais e do número reduzido de candidatos efetivos nas disputas pela presidência da República.

Vale ressaltar, primeiramente, que a coordenação presumida pela teoria do efeito coattails não prescinde de uma condição, qual seja, que as arenas distritais estejam mais ou menos dispostas da mesma maneira que a arena nacional, com os mesmos partidos nas disputas, 
distribuídos da mesma forma entre os distritos e coordenando-se com foco nas eleições nacionais. Exige-se, então, partidos nacionalizados ou com ambição de nacionalização para que essa coordenação partidária possa ser operacionalizada (Hicken; Stoll, 2011). Essa não é a realidade observada no sistema partidário brasileiro e pode ser um caminho explicativo para a não observância da redução de números efetivos de partidos em nosso sistema político.

Em análise sobre a nacionalização partidária no Brasil, Borges (2015) diferencia estratégias eleitorais partidárias de presidencialização e provincialização. Segundo o autor, o impacto das eleições do Executivo nacional ou subnacional nas eleições legislativas depende da estratégia adotada pelo partido.

Partidos com estratégias de presidencialização tendem a sofrer maior influência das eleições presidenciais e partidos com estratégias de provincialização tendem a ter maior impacto das eleições de governador (Borges, 2015). O efeito coattails do governador teria assim seus desdobramentos na coordenação partidária entre distritos, porque na medida em que o sistema partidário estadual é influenciado por questões regionais, a coesão das estratégias partidárias entre os diferentes distritos será menor. O resultado disso são distritos muito diferentes entre si, com dinâmicas distintas e muito possivelmente atores diferentes também. Por isso, argumenta-se que, apesar de ser possível observar em média um reduzido número efetivo de partidos em nível estadual, cada distrito pode congregar partidos diferentes, o que gera uma inflação do sistema partidário nacional.

O fato de um partido não concorrer às eleições presidenciais, no caso brasileiro, não o coloca à margem do sistema partidário nacional, isso porque ele pode se estabelecer em nível subnacional, garantindo representantes no Legislativo, uma vez que decisões sobre candidaturas para deputados federais são tomadas pelos partidos em nível estadual e os recursos provenientes do efeito coattails - estrutura de campanha, visibilidade midiática, entre outros - não estão concentrados tão somente no Executivo federal.

Dessa forma, por mais que o número efetivo de partidos concorrendo à Presidência seja reduzido, partidos que não lançam candidatos ao Executivo federal e que não possuem estratégias de nacionalização garantem cadeiras no Legislativo devido ao protagonismo das unidades subnacionais. 
Destaca-se que é possível analisar os problemas de coordenação eleitoral em duas perspectivas: a coordenação em nível local - como votos são convertidos em cadeiras - e em nível intermediário (linkage) - como os partidos organizam-se da esfera estadual para a competição nacional ${ }^{1}$ (Cox, 1999).

De acordo com Cox (1999), a coordenação em nível local promoveria a entrada estratégica dos partidos na corrida eleitoral. A entrada estratégica depende da concepção de vários cenários possíveis de competidores e da expectativa que os partidos têm ou não de conseguir uma cadeira (Cox, 1999). Em distritos majoritários uninominais, no entanto, é muito mais fácil conjecturar sobre os possíveis resultados do que em distritos de eleições proporcionais e grande magnitude, como é o caso brasileiro.

Segundo o autor, um partido apenas entra na competição quando enxerga possibilidades reais de ocupar uma cadeira. Além disso, os partidos considerariam a dispersão de seus votos em listas distintas, o que incentivaria a coordenação entre partidos ideologicamente próximos. Em distritos de grande magnitude com representação proporcional, no entanto, a quantidade de cadeiras disputadas é maior, o que, somado à uma fórmula eleitoral mais permissiva, aumenta a probabilidade de inserção de partidos minoritários. Nesse sentido, pode haver incentivos para um maior número de partidos efetivos em nível local.

Os vários sistemas eleitorais distritais serão, dessa forma, agregados em nível nacional e o aumento da fragmentação depende do grau de nacionalização ${ }^{2}$ dos partidos, assim como da forma como estes se coordenam entre distritos. Se considerarmos um cenário hipotético de grande coordenação e partidos nacionalizados, teríamos um panorama em que a configuração do sistema partidário nacional refletiria a média de partidos efetivos em nível local. No entanto, os distritos eleitorais no Brasil são bastante díspares e muitos partidos não são nacionalizados, o que faz com que o número efetivo de partidos em nível nacional seja superior à média dos distritos ${ }^{3}$.

\footnotetext{
${ }^{1}$ Cox (1999) apresenta ainda um terceiro nível de coordenação, o nacional, no qual os partidos buscam posições no governo.

${ }^{2}$ A nacionalização dos partidos é observada em duas dimensões: horizontal e vertical. A primeira refere-se à homogeneidade de votação nas várias eleições subnacionais, ou seja, o alcance dos partidos em diferentes distritos. Por sua vez, a segunda diz respeito à coordenação nas eleições dos diferentes níveis federativos (Borges, 2015).

${ }^{3}$ Cox (1999) observou uma inflação de $48 \%$ no número de partidos efetivos na agregação dos partidos do nível local para o nacional.
} 
Os partidos nacionalizados são aqueles que conseguem sustentar candidaturas à Presidência e adotam estratégias nacionalizadas de coordenação. Segundo a literatura sobre o efeito coattails presidencial, esses partidos moldariam o sistema partidário nacional, na medida em que "forçam" o alinhamento dos demais partidos, reduzindo o número efetivo de candidatos na disputa nacional e, consequentemente, enfraquecendo os demais partidos que não possuem estratégias nacionalizadas, o que reduziria a fragmentação partidária e promoveria um sistema mais coeso.

O grau de nacionalização partidária pode ser impactado também pelo grau de centralização política e econômica do governo (Chhibber; Kollman, 1998; Harbers, 2010). No entanto, no Brasil, apesar de observarmos um aumento da centralização fiscal pelo governo federal, é possível observar uma alta descentralização política e administrativa e ainda certa descentralização fiscal, o que confere protagonismo ao nível estadual.

Isso porque os governadores são capazes de mobilizar recursos que impactam a dinâmica eleitoral, não se observando uma dependência absoluta do cenário eleitoral federal. As regras eleitorais permissivas também corroboram para estratégias de conexão com atores locais e não nacionais. Além disso, observa-se no caso brasileiro significativa autonomia das lideranças partidárias estaduais nas principais decisões eleitorais - como organização de listas de candidatos a deputados federais (Samuels, 2003). Esse é outro aspecto que fortalece a regionalização partidária, uma vez que decisões de impacto na esfera nacional são tomadas em nível estadual.

No Brasil, estudos recentes consideram a importância tanto das eleições do Executivo federal quanto do Executivo estadual e apontam que os partidos respondem de formas distintas aos incentivos das eleições presidenciais, podendo adotar diferentes estratégias de sobrevivência na arena eleitoral, fortalecendo, por exemplo, sua atuação na esfera subnacional (Borges, 2015).

As chamadas estratégias de provincialização permitiriam a sobrevivência de partidos que não lançam candidatos para a Presidência independentemente do apoio dos partidos nacionalizados. Segundo o modelo, a concentração de esforços em estratégias nacionais ou regionais depende do grau de descentralização do governo e da capacidade organizacional dos partidos em viabilizar candidaturas à Presidência (Borges, 2015). 
Dessa forma, apesar da institucionalização das eleições presidenciais, do número reduzido de candidatos viáveis nessa disputa e de alguma dose de coordenação partidária em torno dessas candidaturas, é possível notar que o sistema político brasileiro oferece considerável complexidade ao eleitor. Com efeito, o cenário subnacional de fragmentação partidária acaba tomando maiores proporções quando agregado em nível nacional, resultando em um grande número de partidos que participam das competições políticas.

\section{Comportamento eleitoral e o voto para presidente no Brasil}

Muito embora existam diferentes interpretações a respeito do nível de estruturação do sistema partidário brasileiro (Carreirão, 2014; Melo; Câmara, 2012), surge como ponto de consenso na literatura a constatação de que o nosso sistema político convive com um número expressivo de partidos (Figueiredo; Limongi, 1999; Melo; Pereira, 2013; Power, 2011).

Seja em virtude da existência de uma legislação eleitoral que favorece o surgimento de novas agremiações partidárias, seja em função da presença de outros incentivos de ordem institucional (como acesso ao fundo partidário, a financiamento público de propaganda eleitoral nos meios de comunicação, entre outros), o fato é que, atualmente, 35 partidos estão registrados no Tribunal Superior Eleitoral e aptos a concorrer às eleições.

Como destacado acima, a combinação de elementos institucionais que viabilizaram a ampliação da oferta eleitoral e a existência de regras que permitem arranjos diversos nos pleitos contribuíram para o aumento da fragmentação partidária no Brasil. Vale destacar, ainda, que "as instituições federativas e o caráter coalicional do presidencialismo brasileiro possibilitam a sobrevivência de partidos que adotam estratégias nacionais e estaduais fracamente integradas" (Borges, 2015, p. 678), o que acrescenta mais uma dose de complexidade à configuração do jogo político.

Em trabalho seminal para os estudos sobre comportamento político, Campbell e seus coautores (1960) identificaram que, em geral, os indivíduos apresentam baixos níveis de 
informação no que tange a assuntos políticos. Os autores enfatizaram que os eleitores, em sua maioria, conhecem muito pouco a respeito de candidatos e suas plataformas políticas.

O cenário anteriormente descrito impõe altos custos para o acompanhamento do grande número de questões que permeiam a vida pública. Tendo em vista que os indivíduos são processadores limitados de informação (Lau; Redlawsk, 2001), é razoável concluir que o sistema político se organiza de modo a fornecer mecanismos que permitem a formação de preferências sem exigir dos indivíduos um conhecimento enciclopédico sobre política (Lupia; McCubbins, 1998; Lupia, 1994).

A partir da utilização de heurísticas, instrumentos que simplificam o processo de tomada de decisão para os indivíduos, os cidadãos menos informados podem desenvolver atitudes semelhantes às daqueles que possuem tempo e disposição para acompanhar questões políticas de maneira mais atenciosa (Lupia, 1994).

Vale destacar que os cidadãos não formam suas preferências de forma alheia ao contexto no qual vivem. Com isso, pretende-se frisar que o processo que envolve a tomada de decisões sobre assuntos políticos não se desenvolve numa espécie de vácuo institucional (Lupia; McCubbins, 1998). Assim, argumenta-se que o arranjo de regras e procedimentos que disciplinam a vida pública fornece, no mínimo, o palco para manifestação de preferências e atitudes políticas.

No que tange ao contexto político brasileiro, afirma-se que uma heurística partidária não serviria adequadamente para orientar os eleitores a decidirem seus votos, notadamente em função da baixa identificação partidária verificada no país (Desposato, 2009), da notável fragmentação do seu sistema de partidos, assim como da pouco substantiva diferenciação dos partidos políticos nacionais, que são estimulados a se posicionarem no centro do espectro ideológico (Carreirão, 2014).

Sobre o contexto político brasileiro, então, considera-se que, diante da provável ineficiência de uma heurística partidária, a heurística de disponibilidade (Brady; Sniderman, 1991) surge como alternativa com interessante potencial explicativo para se conhecer as preferências do eleitorado. 
Por meio da utilização deste shortcut, os indivíduos promovem uma avaliação do incumbente que almeja a continuidade de seu mandato. A heurística de disponibilidade, desse modo, associa-se à "facilidade de reconhecimento do nome do candidato que concorre à reeleição e a visibilidade maior de seu nome" (Rennó, 2009, p. 41).

No entanto, salienta-se que, em disputas nas quais se observa a participação de um grande número de candidatos, a utilização deste atalho cognitivo pode perder capacidade explicativa.

Neste momento, emerge como um interessante instrumento facilitador do processamento de informações e da tomada de decisões a heurística de apreço (Brady, Sniderman, 1991). Pode-se esclarecer que esse atalho se manifesta a partir da afeição de um eleitor com relação a certos atores políticos, coletivos ou individuais, seguida pela observação de quem esses atores apoiam nas eleições. Esta heurística está associada, por exemplo, à figura do cabo eleitoral, ligada também à transferência de votos.

A despeito da fragilidade dos vínculos entre eleitores e partidos apontados por Paiva e Tarouco (2011), em estudo sobre a decisão do voto para deputado federal, alguns autores afirmam que o contexto no qual ocorrem as eleições presidenciais no Brasil têm favorecido a clivagem entre eleitores.

Com efeito, Ribeiro, Carreirão e Borba (2011), assim como Nicolau (2014), argumentam que as organizações partidárias podem atuar como atalhos cognitivos, auxiliando na formação de preferências e na decisão do voto para a chefia do Executivo federal.

Especialmente nos últimos anos, a literatura brasileira e brasilianista tem dedicado esforços ao estudo da ampliação da base eleitoral do Partido dos Trabalhadores verificada especialmente após a eleição do presidente Lula em 2002. Parte considerável dos autores atribui o sucesso nas urnas do mencionado partido ao êxito dos programas de transferência de renda, como o Programa Bolsa Família.

Neste sentido, Nicolau e Peixoto (2007), examinando os pleitos de 2002 e 2006 nos municípios, inferiram que a alteração na base de sustentação geográfica do Partido dos Trabalhadores foi viabilizada por políticas públicas desta natureza. Hunter e Power (2007), 
em trabalho sobre as eleições presidenciais de 2006, também corroboram o sucesso deste partido em função de estratégias redistributivas.

Sobre o tema, Zucco $(2008,2010)$ assevera que a utilização dos recursos institucionais proporcionados aos chefes do Executivo podem criar vantagens competitivas em pleitos, não somente a eles, mas também aos seus parceiros em competições políticas, o que pode indicar a possibilidade de utilização eficiente de uma heurística de governismo. De acordo com Zucco (2010), este atalho cognitivo seria utilizado, em especial por eleitores com menor renda, que respondem mais positivamente à provisão de bens públicos e particularistas empreendida por governos.

Na dúvida sobre a eficácia de uma heurística partidária para se conhecer as preferências do eleitorado, a heurística de disponibilidade (Brady, Sniderman, 1991), conforme mencionado acima, seria uma alternativa com interessante potencial explicativo.

Ao discorrer sobre a relevância deste atalho cognitivo, Rennó argumenta que

a avaliação do incumbente substitui até mesmo a identificação partidária como determinante central da escolha do eleitor nos Estados Unidos. Ou seja, é a avaliação do desempenho pessoal do candidato à reeleição que importa. Se este é o caso em um sistema político com partidos que têm marcas registradas, então é provável que, onde partidos sejam novos e ainda em consolidação, essa heurística seja ainda mais importante (Rennó, 2009, p. 241).

Vale destacar também que, em recente trabalho, Amaral e Ribeiro (2015) afirmaram que a avaliação dos eleitores em relação à gestão de Dilma Rousseff se revelou um excelente vetor explicativo do voto nas eleições de 2014, tanto no primeiro quanto no segundo turno. De acordo com os autores,

uma avaliação regular do governo aumentava a probabilidade de voto em Aécio ou Marina em mais de três vezes, em comparação aos que classificavam a gestão como ótima ou boa; se a avaliação fosse ruim ou péssima, essa proporção superava 17 vezes no caso de voto em Aécio, e 12 vezes no caso de Marina (Amaral, Ribeiro, 2015, p. 118). 
Por sua vez, Borges e Vidigal (2016, p. 29), analisaram dados de 2002 a 2014, e concluíram que "parte expressiva dos eleitores brasileiros não apresenta disposição em apoiar de forma consistente nenhum dos dois principais partidos na arena presidencial", o que sugere a fragilidade do argumento da polarização partidária do eleitorado brasileiro em torno da competição pela presidência da República.

Além disso, as diferentes estratégias e alianças dos partidos no plano subnacional possibilitam o surgimento e a expansão de um número cada vez maior de partidos pequenos, que têm se revelado cada vez mais exitosos nas eleições proporcionais nos últimos pleitos (Paiva; Alves; Benedito, 2016). Assim, os consideráveis contrastes entre as alianças que um mesmo partido estabelece em diversos estados dificultam a possibilidade de que ele sirva como vetor claro e preciso para que os eleitores formem suas preferências e decidam seu voto.

No que tange à divisão do eleitorado, polarização é entendida aqui como a possibilidade de organização e agregação de ideias que guardam entre si características bastante distintas. Em outras palavras, em um ambiente no qual se pudesse falar em polarização em função da preferência partidária dos eleitores, em um primeiro momento, poderíamos observar que os indivíduos manifestariam suas preferências e atitudes políticas tomando as agremiações partidárias como balizadoras para seus posicionamentos. Além disso, para se falar adequadamente em polarização nestes termos, os partidos deveriam guiar os cidadãos a preferências razoavelmente díspares entre si, para dizer o mínimo.

Fiorina e Abrams (2008) descrevem um eleitorado polarizado como aquele que se concentra nos extremos da distribuição. Nesse sentido, nosso objetivo é explorar se é possível observar a concentração do eleitorado brasileiro em extremos de distribuição de algumas características para além do autoposicionamento ideológico e se, nessa análise, é possível sustentar um argumento assertivo da fragmentação do eleitorado.

Os acirrados debates promovidos pela mídia e por meio das redes sociais, em 2014, apresentavam a percepção de uma radicalização do eleitorado, que estratificava os eleitores brasileiros em torno de características de renda, escolaridade, ideologia, entre outros, 
associando determinadas características aos eleitores de Dilma Rousseff e outras aos apoiadores de Aécio Neves.

A crescente utilização das redes sociais como canal de mobilização dos eleitores (Massuchin; Tavares, 2015) não pode ser desprezada pelas produções da Ciência Política, mas é crucial que investiguemos em que medida é possível observar empiricamente o que intuímos a partir do acompanhamento das mídias virtuais.

Pesquisas de intenção de voto publicadas no período anterior às eleições exploravam questões de cunho sociológico na explicação da preferência eleitoral ${ }^{4}$. Nesse sentido, alguns estudos recentes buscaram testar esses aspectos na preferência do eleitorado. Paiva, Krause e Lameirão (2016), por exemplo, exploram como raça, escolaridade e renda estão relacionadas ao sentimento de antipetismo.

Singer (2009), por sua vez, relaciona o voto a uma questão coletiva, argumentando que pertencer a uma classe social influencia a decisão dos eleitores brasileiros quando vão às urnas. O autor sustenta que houve uma espécie de realinhamento eleitoral após o primeiro mandato do presidente Lula, com a adesão das camadas mais desfavorecidas e o simultâneo afastamento da classe média em relação à sua candidatura.

No mesmo sentido, Cavalcante (2015) aponta para a importância do critério renda no posicionamento político dos eleitores brasileiros, essencialmente pela perda de privilégios que a classe média sofreu ao longo dos governos petistas.

Além desses aspectos, a questão geográfica vem se mostrando relevante em estudos eleitorais. Diversos artigos apontam para o avanço do PSDB nas regiões Sul, Sudeste e Centro-Oeste e diminuição da votação do partido na região Nordeste (Nicolau, 2014; Vale, 2015). Apontamentos sobre o apoio do eleitorado nordestino ao PT ganharam ainda mais força nas discussões sobre polarização considerando o desempenho expressivo de Dilma Rousseff na região nas eleições de 2014.

\footnotetext{
${ }^{4}$ Pesquisa do Datafolha, por exemplo, apontava que o perfil do eleitor de Dilma Rousseff seria de baixa renda, baixa escolaridade e predominante na região Nordeste. Resultados disponíveis em: http://www1.folha.uol.com.br/poder/2014/03/1419905-eleitorado-de-dilma-e-o-mais-pobre-e-o-menosescolarizado.shtml
} 
Nesse sentido, para além dos estudos sobre formação de preferência e identificação partidária do eleitorado brasileiro, pretendemos abordar especificamente quais desses aspectos foram de fato determinantes na decisão do voto presidencial em 2014. As estratificações do eleitorado observadas por pesquisas de intenção de voto e debatidos ativamente nas redes sociais de fato impactaram as votações dos candidatos?

Como se pode observar, esta concisa revisão de literatura evidencia que, embora muitos esforços tenham sido empreendidos pelos estudiosos do tema, algumas questões ainda permanecem em aberto. Percebe-se a existência de uma multiplicidade de abordagens e de inferências sobre o comportamento dos eleitores do país, que não sustenta de maneira incontroversa a famigerada divisão do eleitorado brasileiro nas eleições presidenciais.

Desse modo, a análise de natureza exploratória apresentada neste artigo pretende contribuir para o esclarecimento do alegado fracionamento da sociedade brasileira nos pleitos para a definição do Executivo federal em 2014. Pretende-se, dessa forma, colaborar para o debate sobre quais são os elementos que nos auxiliam a compreender a decisão do voto no Brasil.

\section{Metodologia}

Para enfrentar a questão que orientou a elaboração deste trabalho, foram propostos dois modelos de regressão logística com o intuito de examinar quais foram os principais fatores que condicionaram o voto na candidata Dilma Rousseff nas eleições de 2014. A opção por este modelo para a análise empírica se justifica pois estamos interessados em um resultado de características binárias (se o entrevistado votou ou não na candidata eleita).

Para tanto, utilizamos os dados do ESEB 2014 para criar a variável dependente de natureza dicotômica, para cada um dos modelos. Desse modo, o primeiro e o segundo modelos apresentados nos permitem analisar a probabilidade de observar o voto na mencionada candidata, respectivamente, no primeiro e segundo turnos, em função do mesmo conjunto 
de variáveis explicativas ${ }^{5}$ : idade; sexo; renda; região; se havia votado em Dilma na eleição anterior; ideologia; escolaridade e interesse por política ${ }^{6}$.

Ressalta-se que, além da variável dependente, algumas variáveis explicativas foram reorganizadas de maneira dicotômica com o intuito de cumprir com o objetivo proposto no início deste artigo: verificar se houve uma estratificação da sociedade brasileira severa a ponto de podermos falar em um país dividido.

A opção pelo tratamento de algumas variáveis categóricas de forma binária também se justifica por outras razões de natureza metodológica. Destacamos, principalmente, que as variáveis dummy proporcionam uma maior facilidade na interpretação dos resultados e na identificação de possíveis diferenças entre as duas categorias, uma vez que permitem a observação do efeito médio do pertencimento (ou não) a um grupo sobre o resultado que se pretende examinar.

Salienta-se, igualmente, que quando tentamos manipular a mesma variável, tornando-a dicotômica de diversas maneiras, o teste F (a proporção entre o que se entende por explicação e ruído atribuído a uma variável ou conjunto de variáveis) sempre mostrará o mesmo valor. Em outras palavras, a proporção do fenômeno explicado a partir daquela variável não pode ser alterada quando modificamos a maneira como ela é dicotomizada.

Poderíamos, sim, viabilizar outras interpretações, de acordo com as múltiplas possibilidades de arranjo entre as categorias originalmente apresentadas na base de dados. No entanto, ainda que as organizássemos a partir de diferentes abordagens ou mantivéssemos as categorias originais, a variável não teria alterado o seu potencial explicativo sobre o resultado. Assim, a opção pela transformação binária pela qual

\footnotetext{
${ }^{5}$ É importante destacar que, para o Estudo Eleitoral Brasileiro de 2014, foram realizadas 3.136 entrevistas no total, sendo 2.506 entrevistas proporcionais em todo o território nacional e complemento de 630 entrevistas no Estado de São Paulo. Assim, a subamostra estadual paulista foi composta de 1.204 casos, possibilitando a identificação das seguintes divisões: capital, região metropolitana e interior. Para se evitar distorções na análise empírica, considerando a super-representação do Estado de São Paulo na amostra, foram considerados fatores de ponderação para cada um dos entrevistados deste estado. Neste sentido, o fator de ponderação 0,3793103 foi utilizado para os entrevistados oriundos da capital de São Paulo. Aos integrantes da amostra provenientes da região metropolitana de São Paulo foi aplicado o fator de ponderação 0,2962963 e aos residentes no interior daquele estado, o fator de ponderação 0,7333333 . Por meio de interações com as variáveis categóricas, podemos corrigir as distorções que seriam observadas caso não aplicássemos os fatores de ponderação, o que geraria resultados fortemente influenciados pelos entrevistados do estado de São Paulo. Não promovemos a interação entre o fator de ponderação e a variável região pois existe colinearidade quase perfeita entre estas, o que inviabiliza a sua consideração no modelo.

${ }^{6}$ Após exame dos dados, verificou- se que nenhuma das variáveis selecionadas apresenta missing values.
} 
submetemos algumas variáveis apenas tem como intuito facilitar a interpretação e comparação entre o pertencimento ou não a um grupo e seu efeito sobre o resultado em exame. Todas as categorias foram organizadas com o objetivo de discutir e problematizar as afirmações que circulavam durante o período das eleições de 2014. A seguir, apresentamos como as variáveis explicativas foram consideradas neste trabalho.

A primeira delas indica de maneira quantitativa a idade, em anos completos, dos entrevistados no momento da coleta dos dados. A segunda variável informa se o entrevistado ou entrevistada são do sexo masculino ou feminino. A variável renda foi organizada para reunir, de um lado, os entrevistados que recebem até um salário mínimo (que corresponde à camada mais desfavorecida da população brasileira, segundo o IBGE) e, de outro, os demais. Por sua vez, a variável região, inicialmente expressa em cinco categorias (Norte, Nordeste, Centro-Oeste, Sudeste e Sul) foi transformada em dicotômica, para identificar se o entrevistado era ou não oriundo da região Nordeste ${ }^{7}$.

A quinta variável também foi reorganizada de maneira dicotômica, para expressar se o entrevistado votou ou não em Dilma Rousseff no primeiro turno das eleições de 2010. A variável ideologia, coletada inicialmente no Estudo Eleitoral Brasileiro de acordo com o autoposicionamento dos entrevistados em uma escala de 0 a 10 (em que 0 significa esquerda e 10, direita), foi reestruturada de forma binária. Foram considerados eleitores orientados à esquerda do continuum ideológico apenas os eleitores que se posicionaram entre os pontos 0 e 4 . O ponto médio da escala foi excluído do grupo de eleitores mais orientados à esquerda, entre outras razões, pela observação de que, sozinho, reúne mais entrevistados do que todos os outros (de 0 a 4 ) somados.

Considerou-se prudente, então, classificar como mais orientados à esquerda os eleitores dos cinco primeiros pontos da escala (de 0 a 4), uma vez que não existem razões suficientes

\footnotetext{
${ }^{7}$ As variáveis relacionadas à renda e região geográfica foram organizadas de maneira binária para viabilizar a análise proposta neste artigo, qual seja, identificar se existiu uma clivagem da sociedade brasileira nas eleições presidenciais de 2014. Circulavam, à época, especulações de que Dilma Rousseff seria favorecida pelos eleitores de baixa renda e da região Nordeste. Ressalta-se que a análise empírica também considerou tais variáveis de uma forma não binária (considerando todas as regiões e categorias salariais), o que não alterou os resultados apresentados neste trabalho. É importante que se frise, conforme mencionado nas linhas anteriores, que poderíamos organizar a variável dummy a partir de múltiplas combinações entre as diferentes categorias originais. Porém, ainda assim, apenas estaríamos alterando a forma como interpretamos o efeito da categoria de nosso interesse sobre o fenômeno, e não o potencial explicativo que aquelas categorias originalmente apresentadas possuem sobre o resultado analisado. Em outras palavras, os testes F para a mesma variável organizada de diferentes maneiras devem indicar o mesmo potencial explicativo para aquela variável.
} 
para se acreditar que a distribuição dos eleitores brasileiros tende à esquerda do espectro ideológico ${ }^{8}$.

A variável escolaridade foi igualmente organizada de forma a considerar, de um lado, aqueles que possuem de ensino superior incompleto a pós-graduação e, de outro, os entrevistados que não chegaram a iniciar o ensino superior.

Por fim, a última variável explicativa selecionada para os modelos de regressão logística indica o quanto os entrevistados se dizem interessados por política. Organizamos essa variável de maneira binária, para agrupar, de um lado, os entrevistados que se declararam interessados e muito interessados e, de outro, os demais.

Desse modo, optamos por modelos de regressão que apresentam variáveis de fácil interpretação, com o intuito de contribuir para a compreensão das condicionantes do voto em Dilma Rousseff no mencionado pleito. De fato, com exceção da primeira variável, que expressa em escala numérica a idade dos entrevistados, os demais vetores explicativos escolhidos para os modelos viabilizam a análise que propusemos ao início deste trabalho, qual seja, examinar se é possível identificar uma divisão do eleitorado brasileiro nas eleições presidenciais de 2014 em torno de determinados fatores.

\section{Resultados e discussão}

A análise empírica conduzida neste trabalho foi realizada em duas etapas. Reunimos as variáveis anteriormente descritas em dois conjuntos. No primeiro, mais restrito, consideramos apenas as seguintes variáveis explicativas: idade, sexo, renda e região. No conjunto mais amplo, além destas, incluímos o voto em Dilma na eleição anterior, ideologia, escolaridade e interesse por política.

\footnotetext{
${ }^{8}$ Estudos recentes indicam que não se observa uma polarização do eleitorado nacional. Pelo contrário, atesta-se uma crescente convergência ideológica ao longo dos anos. Corroborando esta afirmativa, por exemplo, verifica-se que os eleitores que não diferenciam as estratégias do PT e do PSDB constituem o segmento mais expressivo entre os cidadãos brasileiros (Borges; Vidigal, 2016), o que nos permite dizer, no mínimo, que não existe uma acirrada divisão ideológica no Brasil.
} 
Deste modo, pudemos estimar dois modelos mais precisos para analisar o voto em Dilma Rousseff em cada um dos dois turnos da eleição de 2014. Nas linhas abaixo, podemos verificar a organização dos dois conjuntos de variáveis explicativas:

Conjunto 1 (idade; sexo; renda; região);

Conjunto 2 (idade; sexo; renda; região; voto em Dilma-2010; ideologia; escolaridade; interesse por política).

Os conjuntos 1 e 2 foram usados para examinar as probabilidades de voto em Dilma Rousseff tanto no primeiro quanto no segundo turno. Em ambos os casos, o conjunto mais amplo de variáveis demonstrou-se mais eficiente para o estudo do fenômeno, o que se observa pelos resultados dos Likelihood Ratio Tests abaixo transcritos:

I) Likelihood Ratio Test para o voto em Dilma no $1^{\circ}$ turno

$\begin{array}{llllll} & \text { Resid. Df } & \text { Resid.Dev } & \text { Df } & \text { Deviance } & \operatorname{Pr}(>\text { Chi }) \\ 1 & 3128 & 4123.1 & & & \\ 2 & 3120 & 3577.4 & 8 & 545.6 & <2.2 \mathrm{e}-16 * * *\end{array}$

Signif. codes: $0^{(* * *)} 0.001$ (**) $0.01^{(*)} 0.05^{‘} .0 .1^{*}, 1$

II) Likelihood Ratio Test para o voto em Dilma no $2^{\circ}$ turno

$\begin{array}{llllll} & \text { Resid. Df } & \text { Resid. Dev } & \text { Df } & \text { Deviance } & \operatorname{Pr}(>\mathrm{Chi}) \\ 1 & 3128 & 4182.4 & & & \\ 2 & 3120 & 3571.5 & 8 & 610.94 & <2.2 \mathrm{e}-16^{* * * *}\end{array}$

Assim, consideramos adequados os modelos propostos, pois se nota um incremento no potencial explicativo quando passamos de um modelo com apenas idade, sexo, renda e região como preditores para um modelo que considera todo o conjunto de variáveis 
selecionadas, descritas acima. Com efeito, os testes de Likelihood Ratio indicam que os modelos "cheios" são mais vantajosos que os modelos reduzidos para a análise dos fenômenos (voto em Dilma no primeiro e segundo turnos das eleições de 2014).

Ainda sobre a adequação dos modelos propostos, considera-se que um modelo de regressão logística fornece um melhor ajuste para os dados se ele demonstra uma melhoria em relação a um modelo com menos variáveis explicativas. Ao realizarmos o teste de razão de verossimilhança, comparamos a eficiência do modelo completo com a de um modelo mais reduzido. Usualmente, a remoção de variáveis explicativas tende a prejudicar o ajuste do modelo, mas, ainda assim, é prudente testar se a diferença observada no ajuste do modelo é estatisticamente significativa. Em geral, interpretamos um valor de $\mathrm{P}$ inferior a 0,05 como uma evidência a favor do modelo atual, o que corrobora a opção pelo conjunto de variáveis mais amplo para a investigação do fenômeno.

No que diz respeito ao modelo para análise do voto no primeiro turno das eleições presidenciais, observamos que idade, região, o voto na eleição anterior e ideologia impactaram nas chances de apoiar Dilma Rousseff. Com exceção de idade, que apenas se mostrou estatisticamente significativa a 10\%, observamos que ideologia, o voto na eleição anterior e região foram significativas em níveis muito mais exigentes (de 5\% abaixo). 
Modelo 1 - O voto em Dilma Rousseff no 1ํturno de 2014

Devi ance Resi dual s:

$\begin{array}{rrrrr}M n & 1 Q & \text { Medi an } & 3 Q & \text { Max } \\ -1.8728 & -0.7754 & -0.5507 & 0.9933 & 2.2916\end{array}$

Coef $\mathrm{fi}$ ci ents:

( I nt er cept)
i dade
sexo
f pond
renda
regi ão
voto_2010_di I ma
i deol ogi a
escol ar i dade
i nter esse_pol i t i ca
sexol: f pond
f pond: r enda
f pond: voto_2010_di I ma
f pond: i deol ogi a
f pond: escol ari dade
f pond: i nt er esse_pol i ti ca
-- -
Si gni f codes:

Esti mate St d. Error $z$ val ue $\operatorname{Pr}(>|z|)$

$\begin{array}{llll}2.201451 & 0.649534 & 3.389 & 0.000701 * * *\end{array}$

$\begin{array}{llllll}-0.004623 & 0.002653 & -1.743 & 0.081392 .\end{array}$

$\begin{array}{lllll}0.134644 & 0.265545 & 0.507 & 0.612121\end{array}$

$\begin{array}{lllll}-1.378605 & 0.728827 & -1.892 & 0.058552\end{array}$

$\begin{array}{lllll}0.012393 & 0.483422 & 0.026 & 0.979547\end{array}$

$\begin{array}{lllll}0.579996 & 0.106531 & 5.444 & 5.20 \mathrm{e}-08 * * *\end{array}$

$-2.705788 \quad 0.264898-10.214<2 \mathrm{e}-16 * * *$

$\begin{array}{lllll}-1.067031 & 0.417764 & -2.554 & 0.010645 *\end{array}$

$\begin{array}{lllll}-0.486565 & 0.358457 & -1.357 & 0.174658\end{array}$

$\begin{array}{lllll}-0.534990 & 0.312325 & -1.713 & 0.086726\end{array}$

$\begin{array}{lllll}-0.142869 & 0.306126 & -0.467 & 0.640715\end{array}$

$\begin{array}{lllll}-0.492606 & 0.537861 & -0.916 & 0.359739\end{array}$

$\begin{array}{llll}1.190610 & 0.305589 & \text { 3. } 8969.77 \mathrm{e}-05 * * *\end{array}$

$\begin{array}{llll}1.316011 & 0.489892 & 2.686 & 0.007224 * *\end{array}$

$\begin{array}{llll}-0.137224 & 0.417494 & -0.329 & 0.742394\end{array}$

$\begin{array}{llll}0.539114 & 0.352516 & 1.529 & 0.126182\end{array}$

Si gni f. codes: 0 '***' 0.001 '**' 0.01 '*' 0.05 ' ' 0.1 ' 1

Nul I devi ance: 4253. 3 on 3135 degrees of $\mathrm{fr}$ eedom Resi dual devi ance: 3577.4 on 3120 degrees of $\mathrm{freedom}$ Al C: 3609.4

Number of $\mathrm{Fi}$ sher Scoring iterati ons: 4

Teste Chi - Squar e: $1.527689 \mathrm{e}-08$

Fonte: elaboração dos autores

Para interpretar o efeito de cada uma destas variáveis sobre a probabilidade de sucesso, considerado, neste caso, o voto em Dilma Rousseff no primeiro turno, extraímos o exponencial de seus respectivos coeficientes para analisarmos a razão de chance ${ }^{9}$. Desse

\footnotetext{
${ }^{9}$ Com exceção das variáveis idade e região, os seguintes valores correspondem aos coeficientes balanceados pelo fator de ponderação. $\operatorname{Exp}(-0.004623)=0.9953877$ (idade); $\exp (0.579996)=1.786031$ (região); $\exp (1.190610)=3.289087$ (voto em Dilma em 2010); exp $(1.316011)=3.728519$ (ideologia). Em relação à variável idade, não se justifica a aplicação do mencionado fator por uma questão óbvia, o risco de se distorcer a real idade dos entrevistados. No que diz respeito à variável região, não se pode promover a interação com o fator de ponderação em virtude da colinearidade quase perfeita entre elas, conforme explicitado na nota 4.
} 
modo, notamos que ser um eleitor da região Nordeste aumentava em $78 \%$ a razão de chance $^{10}$ de se observar um voto na candidata vencedora naquele pleito. Além disso, ter votado em Dilma na eleição anterior e ter se declarado mais orientado à esquerda do espectro ideológico incrementou em, aproximadamente 3,28 e 3,72 vezes, respectivamente, a razão de chance em favor da probabilidade de ter votado na candidata.

Em relação ao modelo para exame do voto no segundo turno das eleições presidenciais de 2014, a análise dos dados revelou que as seguintes variáveis foram estatisticamente significativas, todas a menos de 5\%: idade; região; voto na eleição anterior; ideologia e interesse por política.

\footnotetext{
${ }^{10}$ A razão de chance é igual a probabilidade de ocorrência de um evento (neste caso, o voto em Dilma) dividida pela probabilidade da não ocorrência do mesmo evento.
} 
Devi ance Resi dual s:

$\begin{array}{rrrrr}\text { M n } & 1 \mathrm{Q} & \text { Medi an } & 3 \mathrm{Q} & \text { Max } \\ -2.0402 & -0.8266 & -0.5302 & 0.8908 & 2.3155\end{array}$

Coeffi ci ents:

(I nt er cept)
i dade
s exo
f pond
r enda
r egi ao
vot o_2010_di I ma
i deol ogi a
escol ari dade
i nt er esse_pol i ti ca
sexol: f pond
f pond: renda
f pond: voto_2010_di I ma
f pond: i deol ogi a
f pond: escol ari dade
f pond: i nt er esse_pol i ti ca
---
Si gni f . codes:

Esti mate Std. Error $\mathrm{z}$ val ue $\operatorname{Pr}(>|z|)$

$\begin{array}{llll}3.225881 & 0.671282 & 4.806 & 1.54 \mathrm{e}-06\end{array} * * *$

$\begin{array}{llll}-0.009246 & 0.002655 & -3.483 & 0.000496 * * *\end{array}$

$\begin{array}{lllll}-0.095085 & 0.265410 & -0.358 & 0.720150\end{array}$

$\begin{array}{lllll}-1.984267 & 0.750341 & -2.644 & 0.008182 & * *\end{array}$

$\begin{array}{lllll}-0.318712 & 0.490029 & -0.650 & 0.515439\end{array}$

$\begin{array}{llll}0.724354 & 0.109367 & 6.623 & 3.52 \mathrm{e}-11\end{array} * * *$

$-2.8358520 .262264-10.813<2 \mathrm{e}-16 * * *$

$\begin{array}{lllll}-0.968106 & 0.423222 & -2.287 & 0.022169 *\end{array}$

$\begin{array}{lllll}-0.879843 & 0.358809 & -2.452 & 0.014202 *\end{array}$

$\begin{array}{lllll}-0.680776 & 0.314055 & -2.168 & 0.030182\end{array}$ *

$\begin{array}{lllll}0.243664 & 0.306566 & 0.795 & 0.426720\end{array}$

$\begin{array}{llll}0.019337 & 0.547239 & 0.035 & 0.971813\end{array}$

$\begin{array}{llll}1.227405 & 0.303040 & 4.050 & 5.12 \mathrm{e}-05 * * *\end{array}$

$\begin{array}{llll}0.994912 & 0.494301 & 2.013 & 0.044139 *\end{array}$

$\begin{array}{llll}0.363556 & 0.415639 & 0.875 & 0.381741\end{array}$

$\begin{array}{llll}0.736858 & 0.354585 & 2.078 & 0.037702 *\end{array}$

Si gni f. codes: 0 ‘***' 0.001 '**' 0.01 '*' 0.05 ' ' 0.1 ' 1

Nul I deviance: 4338.0 on 3135 degrees of freedom

Resi dual deviance: 3571.5 on 3120 degrees of freedom

Al C: 3603.5

Number of Fi sher Scoring i terations: 4

Teste Chi - Square: 2. 25904e- 08

Fonte: elaboração dos autores

Em relação à intensidade do efeito, com exceção da variável ideologia, que ainda assim permaneceu estatisticamente significativa, todas as demais apresentaram incremento na probabilidade de sucesso. Sobre a probabilidade da não ocorrência do evento, salienta-se que, para cada ano adicional dos eleitores, diminuía em $1 \%$ a razão de chance de ter votado em Dilma no segundo turno daquele pleito. Efeitos mais robustos foram observados nos demais preditores, favoráveis à ocorrência do voto na candidata eleita.

De fato, duplicou-se a razão de chance de ser um eleitor oriundo da região Nordeste e ter votado em Dilma no turno decisivo daquele pleito. Por sua vez, orientar-se à esquerda do continuum ideológico aumentou em 2,7 vezes a razão de chance a favor do voto na 
presidente eleita. Já o voto na eleição presidencial de 2010 ampliou em 3,41 vezes a razão de chance de ter continuado a apoiar Dilma Rousseff naquele turno. Por fim, no modelo proposto para análise do voto em segundo turno, observou-se que a probabilidade de ter votado na candidata eleita foi mais de duas vezes maior entre os entrevistados que se declararam interessados ou muito interessados por política, quando comparada a dos demais ${ }^{11}$.

A interpretação dos resultados, expressos em razão de chance, revelam o percentual modesto de poder preditivo das variáveis explicativas, com efeitos menos intensos para a explicação do voto em primeiro turno, o que pode ser conferido nas tabelas acima. Os resultados nos levam a considerar com cautela as afirmações de que o Brasil se encontrava dividido no momento das eleições presidenciais de 2014.

A partir da seleção de elementos que usualmente foram apontados como responsáveis por um alegado fracionamento da sociedade brasileira, é possível questionar a assertiva de que houve a vitória de um grupo facilmente identificável contra os demais. A interpretação dos preditores estatisticamente significativos e a intensidade de seus respectivos efeitos inicialmente não indicam uma divisão clara do eleitorado brasileiro.

Neste momento, julgamos oportuno ressaltar, novamente, que o efeito das variáveis significativas se expandiu, quando comparamos os modelos para análise do primeiro e do segundo turnos. Nesse último, com exceção da variável ideologia, que ainda assim permaneceu estatisticamente relevante, todas as condicionantes importantes para $\mathrm{o}$ primeiro modelo tiveram um acréscimo na sua influência sobre a variável dependente. Destaca-se, inclusive, que o interesse por política passou a ser um relevante vetor explicativo.

Desta forma, é interessante considerar que podemos estar diante de uma evidência de que o formato da competição eleitoral influencia o processo de formação de preferências e a decisão do voto dos indivíduos. Neste sentido, a maneira como opera a disputa pela chefia

\footnotetext{
${ }^{11}$ Com exceção das variáveis idade e região, os seguintes valores correspondem aos coeficientes balanceados pelo fator de ponderação. $\operatorname{Exp}(-0.009246)=0.9907966$ (idade); $\exp (0.724354)=2.063398$ (região); $\exp (1.227405)=3.412363$ $($ voto em Dilma em 2010); exp $(0.994912)=2.704486$ (ideologia); $\exp (0.736858)=2.08936$ (interesse por política).
} 
do Executivo pode ter contribuído para o acirramento das preferências e, por via reflexa, para uma maior divisão do eleitorado. Assim, julga-se razoável concluir que as instituições, em especial as regras que orientam a competição presidencial em dois turnos, podem contribuir para moldar e condicionar o comportamento dos eleitores.

Muito embora possamos reconhecer uma limitação nos dados aqui analisados, que, de fato, não permitem o exame de dimensões sensíveis e usualmente associadas àquele pleito, como o radicalismo nas discussões em redes sociais e a percepção de polarização propagada por parte de alguns meios de comunicação, consideramos que este trabalho contribui para uma melhor compreensão do panorama existente no momento da realização das eleições presidenciais de 2014.

Por meio da análise empírica apresentada, podemos inferir, com considerável precisão, que não se sustentam as análises que sugerem que o eleitorado brasileiro se encontrava fracionado em grupos diametralmente opostos naquele momento.

\section{Considerações finais}

Ao longo deste artigo, discutimos a possibilidade de identificar uma divisão do eleitorado brasileiro, o que foi intensamente veiculado pelos tradicionais meios de comunicação e também pelas redes sociais durante e após as eleições presidenciais de 2014. Para tanto, propusemos dois conjuntos de variáveis explicativas, um mais amplo e outro mais reduzido, cujos elementos foram apontados como catalisadores da alegada clivagem no mencionado pleito.

É importante salientar, novamente, a limitação dos dados aqui analisados, que não nos permitem examinar a percepção sobre a polarização e radicalismo nas discussões em redes sociais. No entanto, verificou-se, por meio da utilização do ESEB, que, dentre o conjunto de variáveis usualmente apontadas como promotoras de uma estratificação da sociedade brasileira, apenas algumas serviram adequadamente para diagnosticar um fracionamento dos votantes em certos grupos. No primeiro turno, somente idade, região, o voto na eleição anterior e ideologia impactaram, de alguma forma, nas chances de apoiar Dilma Rousseff. 
Em relação ao segundo turno, adotando-se um nível de significância mais exigente, como especificado na seção anterior, as variáveis idade, região, voto na eleição anterior, ideologia e interesse por política demonstraram potencial explicativo para compreender o voto na candidata eleita. Ressalta-se, mais uma vez, que, com exceção de ideologia, a intensidade do efeito de todos os outros vetores sobre o resultado foi ampliada do primeiro para o segundo turno.

Em suma, é possível inferir que apenas parte da famigerada alegação de que o eleitorado brasileiro estava dividido em grupos é verdadeira. Consideramos mais acertada a rejeição da hipótese de que o eleitorado estava segmentado naquele pleito, tendo em vista que a tese da polarização do eleitorado não prescindiria, a nosso ver, da observação de efeitos mais intensos e mais constantes entre os dois turnos em relação às variáveis explicativas utilizadas neste artigo.

Merecem ser destacados, novamente, que os resultados mais expressivos observados em relação aos fatores apontados como influenciadores da decisão do voto ocorreram para o segundo turno do pleito em exame. Em outras palavras, a análise empírica aqui realizada, apesar das limitações a ela inerentes, especialmente aquelas relacionadas à utilização de dados observacionais, evidencia que a disputa em dois turnos contribuiu de forma interessante para a agregação mais consistente e expressiva de grupos de eleitores em torno das características anteriormente analisadas.

Portanto, ainda que se concorde que a competição pela presidência da República tenha se organizado nos últimos anos em torno de um número reduzido de partidos com reais chances de êxito, não se considera apropriado sustentar que a disputa pela chefia do Executivo nacional canaliza vozes de grupos bastante distintos, pelo menos não da maneira como usualmente se afirma.

Considerando as limitações deste estudo, julgamos oportuno investigar futuramente a possibilidade de identificação de demais grupos que poderiam ser considerados como adversários no pleito. Também entendemos que merecem ser examinados o impacto que a competição política e as alianças partidárias no plano subnacional exercem sobre o comportamento dos votantes, o que será realizado em um próximo trabalho. 


\section{Referências}

AMARAL, O. E. DO; RIBEIRO, P. F. Por que Dilma de novo? Uma análise exploratória do Estudo Eleitoral Brasileiro de 2014. Revista de Sociologia e Política, v. 23, n. 2007, p. 107-123, 2015.

AMORIM NETO, O.; COX, G. Electoral Institutions, Cleavage Structures, and the Number of Parties. American Journal of Political Science, v. 41, n. 1, p. 149-174, 1997.

BORGES, A. Nacionalização Partidária e Estratégias Eleitorais no Presidencialismo de Coalizão Fichamento. Dados, v. 58, n. 3, p. 651-688, 2015.

BORGES, A.; VIDIGAL, R. L. Polarização ou Indiferença? Partidarismo e Voto nas Eleições Presidenciais Brasileiras. X Encontro da ABCP. Anais. Belo Horizonte: 2016

BRADY, H.; SNIDERMAN, P. The likeability heuristic. In: SNIDERMAN, P.; BRODY, R.; TETLOCK, P. (Eds.). Reasoning and choice: explorations in political psychology. Cambridge: Cambridge University Press, 1991.

CAMPBELL, A. et al. The American Voter. New York: Wiley Publishing, 1960.

CARREIRÃO, Y. DE S. O sistema partidário brasileiro: um debate com a literatura recente. Revista Brasileira de Ciência Política, v. 14, n. maio-agosto, p. 255-295, 2014.

CAVALCANTE, S. Classe média e conservadorismo liberal. In: CRUZ, S. V.; KAYSEL, A.; CODAS, G. (Eds.). Direita Volver: O retorno da direita e o ciclo político brasileiro. São Paulo: Editora Fundação Perseu Abramo, 2015.

CHHIBBER, P.; KOLLMAN, K. Party Aggregation and the Number of Parties in India and the United States. The American Political Science Review, v. 92, n. 2, p. 329-342, 1998.

COX, G. Electoral rules and electoral coordination. Annual Review of Political Science, v. 2, p. 145-161, 1999.

DESPOSATO, S. Estratégia Eleitoral com Representação Proporcional de Lista Aberta e Distritos Uninominais: subeleitorados e comunicação política. In: INÁCIO, M.; RENNÓ, L. (Eds.). Legislativo Brasileiro em Perspectiva Comparada. Belo Horizonte: Editora UFMG, 2009.

FIGUEIREDO, A.; LIMONGI, F. Executivo e Legislativo na nova ordem constitucional. São Paulo: Editora FGV, 1999.

FIORINA, M. P.; ABRAMS, S. J. Political polarization in the American public. Annu. Rev. Polit. Sci, v. 11, p. 563-588, 2008.

GOLDER, M. Presidential Coattails and Legislative Fragmentation. American Journal of Political Science, v. 50, n. 1, p. 34-48, 2006.

HARBERS, I. Decentralization and the Development of Nationalized Party Systems in New Democracies: Evidence From Latin America. Comparative Political Studies, v. 43, n. 5, p. 606627, 2010. 
HICKEN, A.; STOLL, H. Presidents and Parties : How Presidential Elections Shape Coordination in Legislative Elections. Comparative Political Studies, v. 44, n. 7, p. 854-883, 2011.

HUNTER, W.; POWER, T. Rewarding Lula: Executive Power, Social Policy, and the Brazilian Elections of 2006. Latin American Politics and Society, v. 49, n. 1, 2007.

LAU, R. R.; REDLAWSK, D. P. Advantages and Disadvantages of Cognitive Heuristics in Political Decision Making. American Journal of Political Science, v. 45, n. 4, p. 951-971, 2001.

LUPIA, A. Shortcuts Versus Encyclopedias : Information and Voting Behavior in California Insurance Reform Elections. American Political Science Review, v. 88, n. 1, p. 63-76, 1994.

LUPIA, A.; MCCUBBINS, M. The democratic dilemma: can citizens learn what they need to know? Cambridge: Cambridge University Press, 1998.

MASSUCHIN, M. G.; TAVARES, C. Q. Campanha eleitoral nas redes sociais: estratégias empregadas pelos candidatos à Presidência em 2014 no Facebook. Revista Compolítica, v. 5, n. 2, p. 75-112, 2015.

MELO, C. R.; CÂMARA, R. Estrutura da Competição pela Presidência e Consolidação do Sistema Partidário no Brasil. Dados, v. 55, p. 71-117, 2012.

MELO, M. A.; PEREIRA, C. Making Brazil Work: checking the president in multiparty system. New York: Palgrave Macmillan, 2013.

NICOLAU, J. Vermelhos e Azuis: um estudo sobre os determinantes do voto nas eleições presidenciais brasileiras (2002-2010). $9^{\circ}$ Encontro da Associação Brasileira de Ciência Política. Anais. Brasília, 2014

NICOLAU, J.; PEIXOTO, V. Uma disputa em três tempos: uma análise das bases municipais das eleições presidenciais de 2006. 31 Encontro Anual da ANPOCS. Anais...Caxambu: 2007

PAIVA, D.; ALVES, V.; BENEDITO, S. As coligações proporcionais e os pequenos partidos nas eleições para a Câmara de Deputados 1998-2014. In: Coligações e Disputas Eleitorais na Nova República: Aportes teórico-metodológicos, tendências e estudos de caso. Rio de Janeiro; São Paulo: UNESP, Konrad-Adenauer-Stiftung; Ed., 2016.

PAIVA, D.; KRAUSE, S.; LAMEIRÃO, A. P. O eleitor antipetista: partidarismo e avaliação retrospectiva. Opinião Pública, v. 22, n. 3, p. 638-674, 2016.

PAIVA, D.; TAROUCO, G. Voto e identificação partidária : os partidos brasileiros e a preferência dos eleitores. Opinião Pública, v. 17, n. 2, p. 426-451, 2011.

POWER, T. O presidencialismo de coalizão na visão dos parlamentares brasileiros. In: POWER, T.; ZUCCO JR, C. (Eds.). O Congresso por ele mesmo. Autopercepções da classe política brasileira. Belo Horizonte: Editora UFMG, $2011 .$.

RENNÓ, L. Atalhos cognitivos em contextos eleitorais complexos: as eleições legislativas de 2002 no Brasil. In: INÁCIO, M.; RENNÓ, L. (Eds.). Legislativo Brasileiro em Perspectiva Comparada. Belo Horizonte: Editora UFMG, 2009. p. 237-268. 
RIBEIRO, E.; BORBA, J.; CARREIRÃO, Y. Sentimentos partidários e atitudes políticas entre os brasileiros. Opinião Pública, v. 17, n. 2, p. 333-368, 2011.

SAMUELS, D. Ambition, Federalism, and Legislative Politics in Brazil. New York: Cambridge University Press, 2003.

SANTOS, A. M. Regras eleitorais importam? Modelos de listas eleitorais e seus efeitos sobre a competição partidária e o desempenho institucional. Dados, v. 49, n. 4, p. 721-749, 2006.

VALE, H. F. Territorial Polarization in Brazil's 2014 Presidential Elections. Regional \& Federal Studies, v. 25, n. 3, p. 297-311, 2015.

ZUCCO JR, C. The President's "New" Constituency: Lula and The Pragmatic Vote in Brazil's 2006 Presidential Election. Journal of Latin American Studies, v. 40, p. 29-49, 2008.

ZUCCO JR, C. Poor voter vs. poor places: persinting patterns and recent changes in Brazilian electoral patterns. Metropolis and Inequalities. Anais. São Paulo: 2010.

\section{Os autores}

Vinícius Silva Alves é doutorando em Ciência Política pela Universidade de Brasília e integrante do Laboratório de Pesquisa em Comportamento Político, Instituições e Políticas Públicas (LAPCIPP). vinicius.silvalves@gmail.com

lana Alves de Lima é Mestra em Ciência Política pela Universidade de Brasília e integrante do Laboratório de Pesquisa em Comportamento Político, Instituições e Políticas Públicas (LAPCIPP).delima.iana@gmail.com 